\title{
The EAEU Common Financial Market: What are the Prospects of Sustainable Development?
}

\author{
Nadezhda Lvova*, Zokhid Rakhimov, Natalia Voronova, Ivan Darushin
}

\author{
Saint Petersburg State University, 7/9 Universitetskaya nab., St Petersburg 199034, Russia
}

*Corresponding author. Email: n.lvova@spbu.ru

\begin{abstract}
Finance holds an important place in sustainable development. Sustainable finance issues are taking up more and more space in theoretical and practical research. At the same time, the role and area of research on sustainable finance is still not clearly understood in scientific works. Thus, the theoretical goal of the paper is to justify the importance and timeliness of introducing the concept of sustainable finance in science, including the study of sustainable development. Given the fact that sustainable finance can become a driver for the development of financial markets in emerging countries, we settled on the EAEU countries and the peculiarities of their financial markets' development. The research methodology is based on an analysis of existing approaches to segmentation of the main directions of sustainable finance development and their adaptation to the EAEU conditions. As a result, the main priorities of the EAEU countries in the framework of sustainable development goals were identified. Based on this, there were drawn the conclusions about the role of financial markets of different countries in supporting sustainable development in the EAEU.
\end{abstract}

Keywords: the Eurasian Economic Union (EAEU), sustainable development, sustainable finance, financial

market, integration, Sustainable Development Goals (SDGs)

\section{INTRODUCTION}

The relevance of the EAEU (hereinafter referred to as the Union) financial market's sustainable development is predetermined by the goals and conditions of the financial integration. In the medium term, it is planned to create a common financial market [1]. However, have the necessary conditions been created for this? Against a backdrop of the successes achieved, the prospects for the common financial market of the EAEU are regarded guardedly. Financial development in the EAEU is uneven both in territories and in market segments, therefore financial integration should be a flexible, asymmetric and progressive process, in which the Russian Federation plays the leading role [2]. Characteristically, the discussion on this issue is mainly limited to the Union, without attracting noticeable attention from other countries [3].

The predominant share of the total financial assets of the EAEU countries is concentrated in Russia (more than $90 \%$ of banking assets and the total capitalization of stock markets), as well as almost the entire volume of trading on stock exchanges, approximately $85 \%$ of banks, $75 \%$ of insurance companies, $89 \%$ of financial infrastructure institutions [4]. However, Russia faces massive challenges [5], which, obviously, does not contribute to the successful financial integration of the EAEU. Under these conditions, the process of forming a common financial market continues to be tuned "from above". It is no coincidence that despite the calls for an "active dialogue with business", the attention of experts and scientific community is focused on harmonizing national legislation and coordinating monetary and financial policies. The steps taken in this regard are, of course, of extreme significance. However, they should be supplemented with financial solutions that correlate with the challenges that are relevant for the EAEU and are able to enhance the financial integration on new principles that are significant for modern society. Such decisions lie on the surface - their choice is implied by the goals of sustainable development [6].

Therefore, in the paper, we address the prospects of sustainable development of the EAEU common financial market, analyzing the prerequisites associated with this in the context of the specifics of the current stage of sustainable finance development, sustainable development priorities and the characteristics of the Union countries' financial systems.

\subsection{Related Work}

The importance of the EAEU financial market sustainable development is predetermined primarily by the specifics of the modern stage of sustainable finance development. This particularity is perhaps characteristic of the intensive growth stage of any complex systems. On the one hand, it is expressed in dynamic and disproportionate development. Some institutions and instruments of the sustainable financial services market are developing better than others. In particular, green bonds markets [7] are more matured than markets of green loans [20]. On the other hand, there comes the stage of theoretical understanding of the 
processes of a new phenomenon formation, from which the science can no longer disengage itself [8].

What can be said about sustainable finance today? Firstly, practice is far ahead of theory. The scientific concept of sustainable finance has been actively developing for no more than four years, while the evolution of sustainable finance has been led in practice at least since the beginning of the 2000s [9]. Secondly, despite a distinct scientific interest in certain aspects of the problem (including green, climate, social finance), a clear understanding of the sustainable finance phenomenon has not been developed either in the academic or professional community. It is often difficult to differentiate green and sustainable finance [10]. More precisely, it is difficult to identify what is included in the concept of sustainable finance, except for its green aspect. Moreover, in Russia, in contrast to developed countries, the categories of "sustainable finance" and "sustainable financial development" are only beginning to enter into scientific discourse. Nevertheless, a reverse is expected, as it becomes increasingly difficult to ignore new practices even on international level of expertize [11].

According to a study under the United Nations Environment Program Financial Initiative (UNEP FI), the evolution of sustainable finance was marked by four "waves" that occurred at the beginning of the two thousandths, the middle of the first decade of the 20th century, 2012 and 2015 [9]. Initially, sustainable finance was more associated with reputation risk management, drawing public attention to ethical financial behavior. This concept received the main support in the development of responsible investment processes. At the next stage, the emphasis of the concept shifted to the issues of business risk management taking into account ESG principles. The third stage in the formation of the concept of sustainable finance was marked by an interest in active search of investment opportunities consistent with the concept of sustainability, which led to the formation of a market for sustainable financial services. At the fourth stage, this market has entered the phase of institutionalization.

The interconnection of sustainable finance concepts can be represented as a hierarchical model, united by the principle of functional structuralism. This means that the financial system should function integrally, including functions, institutions, instruments [12]. The broadest sense of the sustainable finance is embedded in a functional concept that embraces an institutional one, which in turn has an instrumental cross section.

\subsubsection{Instrumental perspectives on sustainable finance}

The ambiguity of scientific ideas about the content of sustainable finance is fully consistent with the specifics of the stage of their development. However, conceptually new approaches to financial decision-making are beginning to increasingly influence the demand and supply in the financial market (for empirical evidence see: [13]), which reflects the desire of financial services consumers for an inclusive society in which mechanisms to overcome economic, social and environmental challenges will be as flexible and individualized as possible. Often, it is the process of introducing environmental, social and governance principles (ESG principles) into financial decision-making process that is associated with sustainable finance [14]. This approach can be called instrumental, since in this case the instrumental component of financial decisions is emphasized. Priority questions within this interpretation: how to apply ESG principles in relation to traditional financial instruments, and how to construct new financial instruments based on these principles?

\subsubsection{Institutional perspectives on sustainable finance}

In the institutional interpretation, sustainable finance refers to those financial conditions that ensure the achievement of sustainable development goals. Simultaneously, main emphasis is placed on "longsighted" risk management and the duration of financial instruments, since it is believed that sustainable finances are designed to exclude financial "short-termism" [15; 16]. Another emphasis, which is a reprise in almost every work on sustainable finance, is the assessment of investment needs to achieve the goals of sustainable development (resource interpretation), which allows us to consider the studied category through the prism of responsible financing. The flip side of this process is socially responsible investment (SRI), the study of which currently provides perhaps a clearer picture of the sustainable finance content than the instrumental approach. Moreover, the SRI concept in their broad understanding integrates the strategy of implementing ESG principles in financial decision-making, but is not limited to this strategy [in more detail see: 17].

\subsubsection{Functional perspectives on sustainable finance}

Finally, we can talk about the functional interpretation of sustainable finance, reflecting the transformation of financial systems, which in the conditions of sustainable development of society should acquire new economic, social, environmental functions, contributing to the inclusive and sustainable development of society [18]. In the context of functional interpretation, the literature discusses the development of green, ethical, religious, inclusive, gender, transformative finances, which are not always positioned by the authors as part of the discussions on sustainable financial development, but logically combined by a common request for a new model of financial development, which or otherwise consistent with inclusiveness and sustainability. Obviously, the implementation of new functions that determine the specifics of this model is impossible without new institutions and tools. Thus, the functional, institutional and instrumental interpretations of sustainable finance are 
indissolubly tied with each other [12], reflect the vector of development of the market for sustainable financial services and allow only conditional theoretical boundaries to be drawn between existing definitions and meanings of key terms.

\subsection{Our Contribution}

Analyzing the content of the sustainable finance concept, it is important to emphasize its continuity and consistency with respect to the concept of sustainable development, which makes it possible to pose the sustainable finance as a new paradigm of financial science and at the same time a new paradigm of financial development. Thus, the recognition of the Sustainable Development Goals' (SDG) relevance and importance inevitably raises the issue of sustainable financial development, and vice versa ignoring this issue puts in question the achievement of the SDG.

Using this prerequisite, we ask ourselves about socioeconomic and environmental priorities of the EAEU financial market's sustainable development. Notably, existing research provides a map of these priorities according to the level of financial systems development [18]. However, these priorities do not reflect the financial characteristics of individual countries. We take a different approach, according to which priorities for achieving the sustainable development goals are ranged. We find this approach to be more relevant because it allows to integrate the objectives of sustainable development of the EAEU financial market into the SDG system.

We also argue that the prospects of the EAEU financial market's sustainable development corresponds with best international practice in this field and special features of national financial systems of the Union. In this regard, we systemize the development vectors of sustainable finance and the problems of implementing successful initiatives in the EAEU countries.

\subsection{Paper Structure}

The rest of the paper is organized as follows. Section 2 introduces the preliminaries used in this paper. Section 3 presents major results. Section 4 concludes the paper and presents direction for future research.

\section{BACKGROUND}

\subsection{The Methodology for Priority SDG Challenges Assessment}

Unlike UNEP analysts who rank the priorities for financing sustainable development projects by the volume of necessary costs, let us consider the priority challenges that the Union countries face in achieving the SDGs. We rank the identified challenges in descending order of joint significance (tab. 1).

The identification of joint challenges in achieving the SDGs gives a preliminary idea of the significant development vectors of the EAEU common financial market. It can be assumed that it is precisely in order to overcome priority challenges, why the introduction of the concept of sustainable finance will be in demand first of all, according to which the socio-economic importance of financial mechanisms is not limited to combating income inequality, increasing economic growth and national welfare. This concept can be demanded in the implementation of infrastructure projects, the fight against climate change, the destruction of ecosystems and gender inequality, etc.

However, at this stage the case is not in setting hypotheses about the importance of sustainable financial development, the verification of which requires further research in more details. Particularly, it is necessary to take into account the comparative importance of the SDGs for the main players in the emerging common EAEU market. The predominant share of the total financial assets and financial institutions of the Union falls on the Russian Federation, which significantly affects the choice of investment objects and trends in financial development.

\subsection{The Relevance of Financial Development Model Assessment}

The financial systems of the Union countries operate according to a so-called "neo-continental model", which, against the backdrop of institutional imperfections related to the decisive importance of state ownership, non-market financing mechanisms, low competition, an increased share of banking assets, is notable for a special role of development banks in the investment process, the underdevelopment of direct financing mechanisms, high market concentration, a relatively small variety of financial instruments. The share of banks in the total volume of aggregate financial assets of the EAEU countries is approaching $90 \%$; financial markets and non-bank financial intermediaries are relatively underdeveloped, including in the Russian Federation, which is significantly distinguished by the level of financial development. The literature notes that in the EAEU countries there are few institutions of collective investment; in general, foreign exchange markets dominate, and equity and corporate bond markets are not developed; derivatives markets, with the exception of the Russian one, are absent or characterized by single transactions.

In recent years, the key features of neo-continental financial systems have become more distinct in the countries of the Union. As an interesting illustration, we note that Russia is showing a steady increase in the level of deposits amid falling of equity market capitalization (in relation to GDP). Since 2013, the financial depth of deposit financial institutions in the Russian Federation has exceeded the depth of the stock market. The observed change in the financial structure of the Russian economy indicates not 
only a slowdown in financial development, but also a decrease in the level of national financial well-being, which is a significant factor the financial services market progress. The banking sectors dominant in the EAEU financial systems have a high and ultrahigh concentration (in Russia and other countries of the Union, respectively), which negatively affects the assessment of their effectiveness. At the same time, the number of banks in the countries of the Union is steadily decreasing, and the concentration of assets is increasing.
Finally, the main share of the total financial assets in the EAEU is accumulated by the largest banks of the Russian Federation, whose policies are largely determined by the state as the largest owner. In the context of the studied issues, this means that the success of the sustainable development of the EAEU financial market will largely depend on the role that Russian banks will play in introducing the concept of sustainable finance.

Table 1 Priority challenges in achieving the SDGs for the EAEU countries in 2019

\begin{tabular}{|c|c|c|c|c|c|}
\hline \multirow[b]{2}{*}{ Sustainable Development Goals (SDGs) } & \multicolumn{5}{|c|}{$\begin{array}{c}\text { Countries, their place in the international SDG } \\
\text { achievement ranking, } 2019\end{array}$} \\
\hline & $\begin{array}{c}\text { BY } \\
\text { 23rd } \\
\text { globally, } \\
\text { 1st in } \\
\text { EAEU }\end{array}$ & $\begin{array}{c}\text { KG } \\
\text { 48th } \\
\text { globally, } \\
\text { 2nd in } \\
\text { EAEU }\end{array}$ & $\begin{array}{c}\text { RU } \\
\text { 55th } \\
\text { globally, } \\
\text { 3rd in } \\
\text { EAEU }\end{array}$ & $\begin{array}{c}\text { AM } \\
\text { 75th } \\
\text { globally, } \\
\text { 4th in } \\
\text { EAEU }\end{array}$ & $\begin{array}{c}\text { KZ } \\
77 \text { th } \\
\text { globally, } \\
\text { 5th in } \\
\text { EAEU }\end{array}$ \\
\hline \multicolumn{6}{|l|}{ Goal 1: No poverty } \\
\hline Goal 2: Zero hunger & $\bullet$ & $\bullet$ & $\bullet$ & $\bullet$ & O \\
\hline Goal 3: Good health and well-being & $\bullet$ & O & O & $\bullet$ & o \\
\hline \multicolumn{6}{|l|}{ Goal 4: Quality education } \\
\hline Goal 5: Gender equality & & $\bullet$ & $\bullet$ & ○ & \\
\hline Goal 6: Clean water and sanitation & & $\bullet$ & & $\bullet$ & $\bullet$ \\
\hline \multicolumn{6}{|l|}{ Goal 7: Affordable and clean energy } \\
\hline Goal 8: Decent work and economic growth & $\bullet$ & $\bullet$ & $\bullet$ & O & \\
\hline Goal 9: Industry, innovation, infrastructure & $\bullet$ & o & $\bullet$ & $\bullet$ & $\bullet$ \\
\hline Goal 10: Reduced inequalities & & & o & $\circ$ & o \\
\hline Goal 11: Sustainable cities and communities & $\bullet$ & & & $\circ$ & \\
\hline Goal 12: Responsible consumption, production & & & $\bullet$ & & $\bullet$ \\
\hline Goal 13: Climate action & $\bullet$ & & o & & ○ \\
\hline Goal 14: Life below water & - & - & $\bullet$ & - & - \\
\hline Goal 15: Life on land & & $\bullet$ & $\bullet$ & $\bullet$ & $\bullet$ \\
\hline Goal 16: Peace, justice and strong institutions & $\bullet$ & ○ & o & $\bullet$ & O \\
\hline Goal 17: Partnerships for the goals & & & & $\bullet$ & $\bullet$ \\
\hline Number of goals (average of 9 goals) & 7 & 8 & 11 & 11 & 10 \\
\hline
\end{tabular}

\section{RESULTS}

\subsection{The Priority SDG Challenges for the EAEU}

We rank the identified SDG challenges for the EAEU in descending order of joint significance:

1) Among the priority challenges for all countries of the Union at present are goals under numbers 16 «Peace, Justice and Strong Institutions», 3 «Good Health and Well-Being» (in particular, for Kyrgyzstan (KG), Russia (RU) and Kazakhstan (KZ), they are also among the main challenges, and the situation is cardinal does not change). This group of goals also includes SDG 2 «Zero Hunger» (one of the main challenges for Kazakhstan) and SDG 9 «Industry, Innovation, Infrastructure» (is one of the main challenges for the Kyrgyz Republic).

2) The priority challenges for almost all countries of the Union are SDG 8 «Decent Work and Economic Growth» 
Equality» (one of the main challenges for Armenia, a significant challenge for Kyrgyzstan and the Russian Federation). In addition, one of the significant challenges for all EAEU, except the Republic of Belarus, is SDG 6 «Clean Water and Sanitation».

In a generalized form, these challenges are presented in Figure 1 .

10 «Reduced Inequalities» (one of the main priorities for Russia, Armenia and Kazakhstan), SDG 13 «Climate Action» (refers to the main challenges for Russia and Kazakhstan, to significant for Belarus) and SDG 5 «Gender

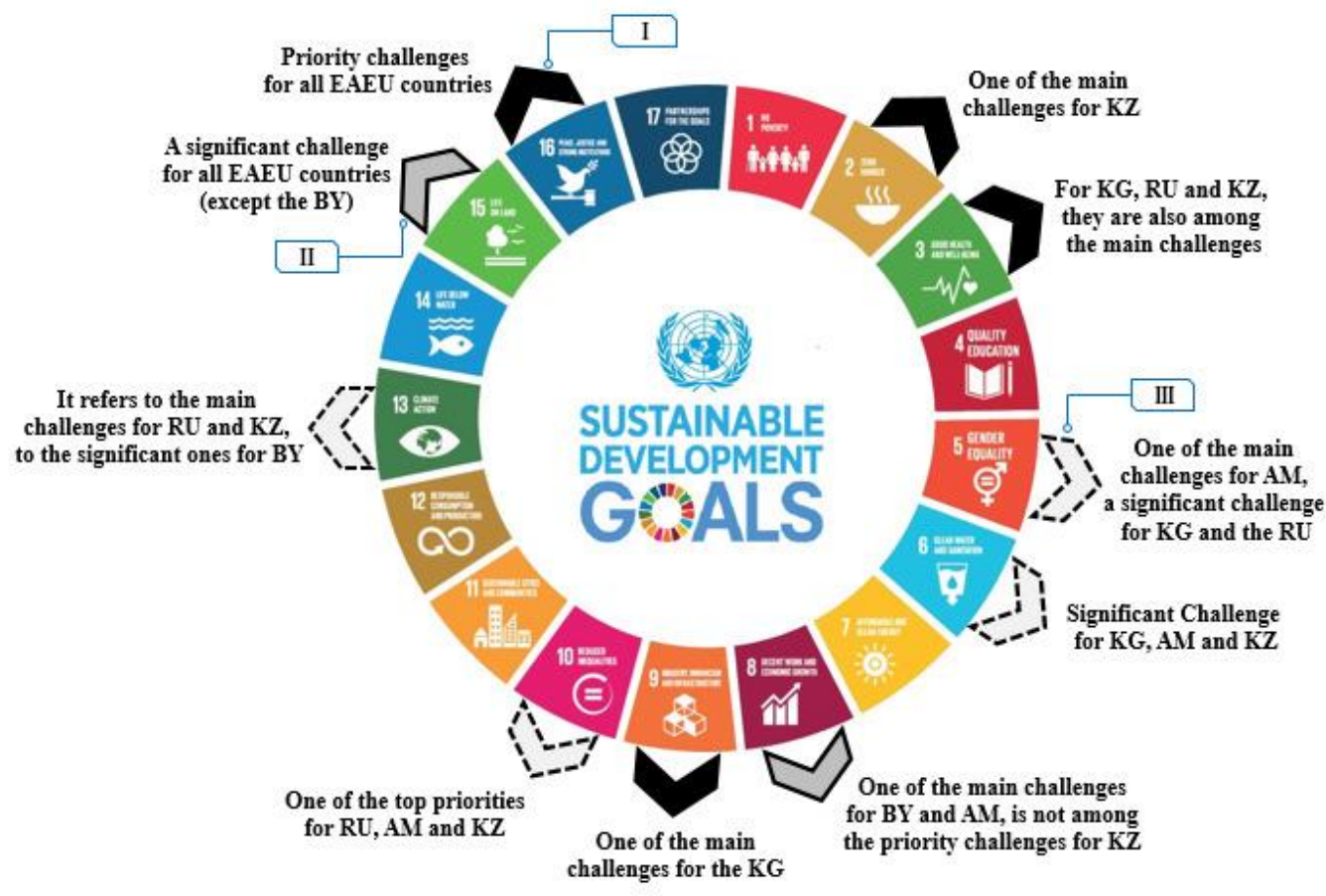

Note:

1. BY - Belarus, KG - Kyrgyzstan, RU - Russian Federation, KZ - Kazakhstan, AM - Armenia.

2. I - Priority challenges for all EAEU countries; II - Priority challenges for almost all countries of the Union; III -Priority challenges for most countries of the Union.

Figure 1 Priority SDGs for EAEU countries Source: Prepared by the authors on [19].

It is important to take into account that for Russia, the main challenges in achieving the SDGs are "Good health and well-being", "Reducing inequality", "Fighting climate change", "Peace, justice and effective institutions". These same goals are among the main priorities for the second most important participant in the future financial market of the EAEU - the Republic of Kazakhstan. "Eradication of hunger", "Gender Equality", "Decent Work and Economic Growth", "Industrialization, Innovation and Infrastructure", "Responsible Consumption and Production", "Conservation of Marine Ecosystems" and "Conservation of Terrestrial Ecosystems" remain significant priorities for Russia.

However, what financial mechanisms exist to achieve these goals? What goals and under what conditions can interest major suppliers of financial resources, whether it is the private sector, financial companies or budgets of different levels? The answers are ambiguous. Many of the popular financial mechanisms are not quite obvious, which, for example, concerns challenges related to the achievement of Peace, Justice and Effective Institutions, the indicators of which include indices for protecting property rights and perceptions of corruption. The attractiveness of investment projects related to the achievement of the SDGs is also ambiguous for potential suppliers of financial resources. Some goals have a pronounced social or environmental focus with a delayed economic effect, others have a more distinct investment potential and, therefore, are more attractive to financial decision-makers.

Nevertheless, the concept of sustainable finance is able to offer a wide range of solutions in non-obvious situations. Within the framework of the concept of sustainable finance, financial mechanisms are being developed to overcome gender and economic inequality. Green financial mechanisms are in demand in the fight against climate change, in the implementation of infrastructure projects and 
ecosystem restoration projects, in the development of responsible production and consumption. It is essential to recall that the EAEU holds a leading position in the world in oil and gas production, as well as in electricity generation. Therefore, the largest EAEU investment projects are also being implemented in the same areas, which actualizes the development of green financial services, combining the established priorities of economic development with the current direction of sustainable development.

\subsection{Financial Potential to Overcome SDG Challenges in the EAEU}

The prospects for active support of this initiative are currently uncertain. Characteristically, not a single Russian bank (like any of the resident banks from other EAEU countries) has joined the international Equator Principles, which impedes the introduction of the concept of sustainable finance in the practice of project financing. The banks of the Union are not represented in the Global Alliance for Banking Values, which promotes the introduction of the sustainable finance concept in banking practice. EAEU financial regulators and banking associations (with the exception of Kyrgyzstan) ignore participation in the Sustainable Banking Network.

If the banks of the Union, for one reason or another, do not seek to join international financial associations, a regional alternative can be proposed. In view of the characteristics of neo-continental financial systems, development banks can play a leading role in combining this level. At the regional level, we are talking primarily about the Eurasian Development Bank (EDB), which has been operating since 2006. It is noteworthy that the EDB, specializing in project finance, emphasizes its high environmental standards and increased interest in green investments. Another key regional financial institution of the EAEU is the Eurasian Fund for Stabilization and Development (EFSD, established in 2009). EFSD is positioned as an institution that promotes not only economic integration, but also long-term financial stability of the Union countries, which by itself meets the concept of sustainable finance. However, the recognition of the significance of this concept in the EFSD documents is not traced, contrasting with current trends in financial policy. According to the authors, the development and implementation of the principles of sustainable financial activities under the auspices of the EDB and the EFSD can attract the attention of the EAEU financial community by mobilizing new drivers for financial integration.

\section{CONCLUSION}

The study showed that the importance of sustainable development of the EAEU financial market is predetermined by the specifics of the modern stage of sustainable finances development. To date, one can observe the distinctive contours of individual segments of the actively growing market for sustainable financial services.
Science can no longer remain aloof from ongoing processes, which is gradually reflected in the literature. The authors revealed three interrelated components of the concept of sustainable finance: instrumental, institutional, functional. Thus, there is a reason to talk about theoretical and practical prerequisites for introducing the concept of sustainable finance into the EAEU financial integration strategy.

The concept of sustainable finance is being developed in line with the concept of sustainable development, which allows us to ask more substantively the question of financial development priorities. In particular, we propose ranking the joint challenges in achieving the SDGs for the countries of the Union, which gives a preliminary idea of the significant development vectors of the EAEU common financial market. Hypotheses in this regard require further research, taking into account the correlation of national priorities and the financial capabilities of the Union countries, the availability of necessary financial mechanisms, and the interest of suppliers of financial resources. Nevertheless, the concept of sustainable finance is able to offer a wide range of solutions on economic, social and environmental issues, including combating inequality, ecosystem destruction and climate change.

The financial systems of the EAEU countries are developing according to a neo-continental model, the characteristic features of which have been strengthened in recent years. Given the proportions of the EAEU financial space, the importance of sustainable development of the common financial market should first of all receive the support of the largest Russian banks, which currently do not show active interest in this, not joining, like other banks of the Union, to relevant international associations. According to the authors, in this situation, a regional alternative is demanded under the auspices of regional development banks. In conclusion, we emphasize once again that the recognition of the importance of the goals of sustainable development raises the issue of sustainable finance. The converse is also true: ignoring this issue, we question the achievement of the SDGs. Therefore, the importance of sustainable development of the EAEU common financial market should receive well-deserved attention.

\section{ACKNOWLEDGMENT}

The reported study was funded by RFBR according to the research project № 19-010-00526.

\section{REFERENCES}

[1] TREATY, 2014. Treaty on the Eurasian Economic Union, 2014. 715 p. Available at: https://www.wto.org/english/thewto_e/acc_e/kaz_e/WT ACCKAZ85_LEG_1.pdf

[2] N.A. Lvova, N.S. Voronova, V.V. Ivanov, The relevance of the sustainable finance paradigm in the EAEU financial market's strategy development. 
[11] H. Kharas, S. Zadec, Aligning financial system architecture and innovation with sustainable development. UNEP FI, 2018. 12 p.

[12] N.A. Lvova, I.A Darushin, N.S. Voronova, A.V. Kazansky, Sustainable finance: theory and international initiatives. Proceedings of the 34th International Business Information Management Association Conference. Ed. Khalid S. Soliman. IBIMA, 2019, pp. 9266-9273.

[13] GSIA, 2018. Global Sustainable Investment Alliance Review, 2018. 26 p. Available at The Global Sustainable Investment Alliance: http://www.gsialliance.org/wpcontent/uploads/2019/06/GSIR_Review2018F.pdf

[14] UN PRI, 2019. About the PRI. Available at: https://www.unpri.org/about-the-pri

[15] Financing a sustainable European economy: Interim Report. - The High-Level Expert Group (HLEG) on Sustainable Finance, 2017. 69 p.

[16] Financing a sustainable European economy: Final Report. - The High-Level Expert Group (HLEG) on Sustainable Finance, 2018. 99 p.

[17] J. Kölbel, F. Heeb, P. Falko, T. Busch, Can sustainable investing save the world? Reviewing the mechanisms of investor impact. July 20, 2019. Available at SSRN: https://ssrn.com/abstract $=3289544$ or http://dx.doi.org/10.2139/ssrn.3289544

[7] G. Rado, Green Bonds - a key tool for financial Bonds Initiative. March 5, 2019. URL: https://www.climatebonds.net/files/reports/cbifinancial_centres_03d.pdf

[8] C. Carpenter, M. Manchini, Mainstreaming sustainable finance. UNEP FI, 2018. 6 p.

[9] The financial system we need. From momentum to transformation. - The UNEP Inquiry Report. - 2nd ed. October 2016. - Vii +87 p

[10] The rise of green finance in Europe. Ed. M. Migliorelli, P. Dessertine. Palgrave Studies in Impact Finance, 2019. $275+\mathrm{xx}$ p.
[18] The financial system we need. Aligning the financial system with sustainable development. - The UNEP Inquiry Report. - October 2015. - Vii + 84 p.

[19] J. Sachs, G. Schmidt-Traub, C. Kroll, G. Lafortune, G. Fuller, Sustainable Development Report 2019. - New York: Bertelsmann Stiftung and Sustainable Development Solutions Network (SDSN), 2019. URL: https://sdgindex.org/

[20] Linklaters LLP, 2019. Sustainable Finance: The rise of green loans and sustainability linked lending. Linklaters Report, 2019. 34 p. Available at: https://www.linklaters.com/en/insights/thoughtleadership/sustainable-finance/the-rise-of-green-loansand-sustainability-linked-lending 